\title{
An imaging proton spectrometer for short-pulse laser plasma experiments
}

H. Chen, A. Hazi, R. van Maren, S. Chen, J. Fuchs, M. Gauthier, J. R. Rygg, R. Shepherd

February 11, 2010

18th Topical Conference on High-Temperature Plasma Diagnostics Wildwood, NJ, United States May 16, 2010 through May 20, 2010 
This document was prepared as an account of work sponsored by an agency of the United States government. Neither the United States government nor Lawrence Livermore National Security, LLC, nor any of their employees makes any warranty, expressed or implied, or assumes any legal liability or responsibility for the accuracy, completeness, or usefulness of any information, apparatus, product, or process disclosed, or represents that its use would not infringe privately owned rights. Reference herein to any specific commercial product, process, or service by trade name, trademark, manufacturer, or otherwise does not necessarily constitute or imply its endorsement, recommendation, or favoring by the United States government or Lawrence Livermore National Security, LLC. The views and opinions of authors expressed herein do not necessarily state or reflect those of the United States government or Lawrence Livermore National Security, LLC, and shall not be used for advertising or product endorsement purposes. 
Abstract for the 18th Topical Conference on High-Temperature Plasma Diagnostics, Wildwood, New Jersey, May 16-20, 2010

\title{
An imaging proton spectrometer for short-pulse laser plasma experiments
}

\author{
Hui Chen ${ }^{a}$, A. Hazi ${ }^{a}$, R. van Maren $^{a}$, S. Chen ${ }^{a}$, J. Fuchs $^{b}$, M. Gauthier ${ }^{b}$, J. R. Rygg ${ }^{a}$ and R. \\ Shepherd ${ }^{a}$ \\ ${ }^{a}$ Lawrence Livermore National Laboratory,Livemore, CA 94551, USA \\ ${ }^{b}$ LULI Ecole Polytechnique, 91128 Palaiseau Cedex, France \\ chen33@1lnl.gov
}

Ultra intense short pulse laser pulses incident on solid targets can generate energetic protons. In additions to their potentially important applications such as in cancer treatments and proton fast ignition, these protons are essential to understand the complex physics of intense laser plasma interaction. To better understand these laser-produced protons, we designed and constructed a novel, spatially imaging proton spectrometer that will not only provide at high-resolution the energy distribution, but also the protons angular characteristics. The information obtained from this spectrometer compliments those from other methods using radiochromic film packs, CR39 films and other protons spectrometers. The basic characterizations and example data from this diagnostics will be presented. This work was performed under the auspices of the U.S. Department of Energy by Lawrence Livermore National Laboratory under Contract DE-AC52-07NA27344, as part of the Cimarron project funded by LDRD-09SI11. 